TO CITE THIS DOCUMENT: Pina, K. and Tether, B. (2016) 'Towards understanding variety in knowledge intensive business services by distinguishing their knowledge bases', Research Policy, 45, 401-413

(DOI: $10.1016 /$ j.respol.2015.10.005)

\title{
Towards understanding variety in knowledge intensive business services by distinguishing their knowledge bases
}

\author{
Katia Pina \\ (katia.pina@mbs.ac.uk) \\ Bruce S. Tether \\ (bruce.tether@mbs.ac.uk)
}

\begin{abstract}
Knowledge intensive business services (KIBS) are known to play a significant role in innovation systems. Past research has however mostly treated KIBS as a homogenous group; it is now time to understand better the variety that exists among KIBS. In this study, we apply a mix of qualitative and quantitative methods to examine a dataset of 362 UK-based KIBS firms active in three 'sectors': architecture and engineering consulting; specialist design; and software and IT consulting. By applying content analysis techniques to information drawn from firms' websites, we identify each firm's primary 'knowledge base', be that analytical, synthetic or symbolic knowledge. We then relate the firms' primary knowledge base to their engagement in R\&D, design and innovation, and examine how the 'drivers' of innovation vary between firms with different primary knowledge bases. The paper thereby contributes to the literature, first by identifying empirically 'knowledge bases', then relating these to the variety that exists among KIBS. The paper concludes by highlighting issues for further conceptual, methodological and empirical research.
\end{abstract}

Keywords: Knowledge bases; Knowledge intensive business services (KIBS); Diversity; Innovation; Content analysis. 


\section{Introduction}

Over the last 20 years or so, the economic significance of business and professional service, and especially 'knowledge intensive business services' (hereafter KIBS), has been increasingly appreciated, first by economic geographers (e.g., Gillespie and Green, 1987; Daniels and Moulaert, 1991; Wood, 2002; 2009; Doloreux et al., 2010), then by innovation and management scholars (Bessant and Rush, 1995, Miles et al., 1995, Howells, 2006; Tether and Tajar, 2008; Muller and Doloreux, 2009; Love et al, 2011), and latterly by policymakers (e.g., European Commission, 2009; United Nations, 2011; BIS, 2012; OECD, 2012; Schricke et al., 2012). ${ }^{1} \quad$ These studies were often oriented to understanding how KIBS differ from product-based manufacturing firms, or from operational services, and therefore largely treated KIBS as a homogeneous group. These studies have advanced understanding of how innovation occurs in KIBS, and how KIBS contribute to systems of innovation by, inter alia, helping their clients to innovate. However, because the primarily aim has been to differentiate KIBS from other types of firm or industry, most studies have either considered KIBS as a whole, divided them by 'industry' (as defined by standard industrial classifications), or applied broad categorisations such as P-KIBS (i.e., professional KIBS) and T-KIBS (technical KIBS). Few studies have considered the specifics of the various KIBS activities from a conceptual perspective, and how these specifics - including the nature of their knowledge bases - may influence their structure and behaviours (Von Nordenflycht, 2010, Malhotra and Morris, 2009, Tether et al., 2012, Consoli and Elche-Hortelano, 2010). As KIBS constitute a large and rapidly growing component of advanced economies, ${ }^{2}$ we consider that there is a need to move on from understanding how KIBS differ from other types of firm, to understanding better how they themselves are differentiated. By better understanding how KIBS are differentiated, policy can be better attuned to their various needs.

In this paper, we develop the idea that KIBS vary substantially in their 'knowledge bases'; that is the 'type', 'form' or 'mode' of knowledge at the core of their activities (Strambach, 2008; Consoli and Elche-Hortelano, 2010; Tether et al., 2012; Consoli and

\footnotetext{
${ }^{1}$ For example, a recent UK Government report states that: Professional and business services are a source of UK comparative advantage and the sector has in the past made a very significant contribution to UK growth. .... [These firms also] provide a significant input to other sectors ... and therefore offer a channel for transmitting efficiency gains and spillovers to a wider group of industries (BIS, 2012, p. 33).

${ }^{2}$ For example, 'Professional and Business Services' directly account for $11 \%$ of UK gross value added and provides nearly $12 \%$ of UK employment, and have grown about twice the rate of the economy as a whole. (BIS, 2013, pg. 6)
} 
Elche, 2013). We also develop an empirical methodology for identifying a firm's primary knowledge base, which relies on extracting information from company websites. We apply this to a dataset of 362 UK based KIBS active in three 'sectors': architecture and engineering consulting; specialist design; and software and IT consulting. We then relate these 'knowledge bases' to variety among the firms, in terms of their characteristics, and the activities they invest in, including their propensities to innovate, and to the activities they engage in to innovate, finding significant differences.

The paper is structured as follows. In Section 2, we contextualise the study in the literature on 'knowledge bases'. Section 3 then outlines the methods and measures used to identify 'knowledge bases', while Section 4 relates these to empirical differences in firm characteristics and behaviours. Section 5 discusses the findings, and Section 6 concludes the paper, including an outline of issues for further research.

\section{Conceptual foundations}

Innovation studies has long appreciated that there are different 'types', 'forms' or 'modes' of knowledge, and that these are associated with different activities, or approaches to innovation. This observation is, for example, fundamental to Pavitt's seminal taxonomy (Pavitt, 1984) and to the literature that followed (e.g., Jansen et al., 2007; Castellacci, 2008). Until recently, however, the literature on KIBS has, with a few exceptions (e.g., Strambach, 2008; Consoli and Elche-Hortelano, 2010; Tether et al., 2012; Consoli and Elche, 2013), either treated these firms/sectors as a homogeneous grouping, divided them according to the 'standard industrial classification', or applied somewhat awkward distinctions, such as between P-KIBS: 'professional service firms' (e.g., legal and accountancy services), and TKIBS: 'technical service firms' (e.g. such as R\&D services and computer services) (Miles et al., 1995). ${ }^{3}$ We conjecture that, just as there is typically a connection between the type of product, the technologies of production, and the organisation of production in manufacturing

\footnotetext{
${ }^{3}$ This categorisation is awkward because it is not always clear where to classify KIBS. For example, in the UK, architecture is a 'profession' in that an architect needs to qualify and be registered to practice, but architects can also be considered both creative and technical service providers. Design consultancy, meanwhile, is not a 'profession' as neither qualifications nor registration is required to practice as a design consultant, but while some of these are highly technical, others are not. Perhaps both architects and designers could be accommodated in a new classification of C-, or 'creative', KIBS, but this misses the point. These taxonomic difficulties imply the need for a stronger conceptual grounding of the characteristics of, and variety amongst, KIBS and 'professional service firms' (Malhotra and Morris, 2009; von Nordenflycht, 2010)
} 
(Woodward, 1965; Davies and Frederiksen, 2010), ${ }^{4}$ a dimension of meaningful and significant variety among KIBS is the 'type' of knowledge central to their activities. While these businesses are unified in their characteristics of being knowledge- (rather than capital-) intensive, they may be qualitatively different on the basis of utilising different 'types', 'modes' or 'forms' of knowledge. Furthermore, we conjecture that this variation will be associated with differences in both their propensity to innovate (as conventionally measured), and with differences in their approach to innovation. R\&D, for example, is more likely to be important to KIBS based on analytical knowledge, and likely to be rare among those based on symbolic knowledge.

Various taxonomies of knowledge have been proposed (Kakabadse et al., 2003), but in this paper we build on the distinction made by Asheim and colleagues (Asheim and Coenen, 2005; Asheim et al., 2007) between 'analytical', 'synthetic' and 'symbolic' knowledge (Strambach, 2008; Strambach and Dieterich, 2011; Tether et al., 2012). With its roots in the literature of regional innovation systems, this typology has been used to classify the 'knowledge bases' that predominate in different industries and regions; the typology has also occasionally been applied to firms (e.g., Liu et al., 2013). It provides an alternative to other categorisations, such as that between tacit and codified knowledge (Polany, 1967); or that between 'know-what', 'know-why', 'know-how' and 'know-who' discussed by Lundvall and Johnson (1994).

We favour Asheim and colleagues' conceptualisation because it includes a 'type of knowledge' or 'knowledge base' which is different from those included in previous categorisations and which we consider likely to be particularly important to some KIBS namely 'symbolic knowledge'. By including 'symbolic knowledge', Asheim and colleagues not only extend beyond the widely used but perhaps increasingly stale discussion of tacit and codified knowledge, but also allude to the social construction of at least some types of knowledge -especially expressive or symbolic knowledge, which is less rational or functional (Cappetta et al., 2006; Jahnke, 2013; Verganti and Öberg, 2013). We briefly review the conceptualisation of 'knowledge bases' as a whole, before outlining 'analytical', 'synthetic' and 'symbolic knowledge' specifically.

\footnotetext{
${ }^{4}$ This does not mean there is always a one to one mapping between these. For example, in the car industry, assembly lines predominate, but some manufacturers, such as Morgan, still use craft methods.
} 


\subsection{Knowledge bases - synthetic, analytical and symbolic (the SAS model)}

The understanding that innovation is organised differently in different sectors or activities is foundational in innovation studies. Pavitt (1984), for example, distinguished between science-based, scale-intensive, supplier-dominated and specialist supplier sectors, where the former rely heavily on $\mathrm{R} \& \mathrm{D}$, often conducted in dedicated laboratories, while the latter are engaged in problem solving, developing solutions for and with their clients. The nature of these activities is also influenced by both the nature of their knowledge bases, and the organisation of knowledge production. Science-based activities utilise science to develop largely cumulative knowledge, whereas specialist suppliers search for solutions which may be ad hoc, and highly context specific. Science-based knowledge production tends to be centralised, whereas specialist suppliers are dispersed. Other studies have made related distinctions. Jansen et al (2007), for example, differentiate a 'science and technology' mode of innovation based on the production and use of codified scientific and technical knowledge, from a 'doing, using and interacting mode', which relies on informal processes of learning and experience-based know-how. Malerba (2002), meanwhile, emphasises the interplay between the knowledge base of a sector, its pattern of innovation, and wider organisation. To date, most of this work has been undertaken in the context of manufacturing, or productbased industries, but some contributions, including Evangelista (2000), Hollenstin (2003), Castellacci (2008) and Tether and Tajar (2008), have sought to extend and apply these ideas to services. Within this tradition, Asheim and colleagues' first distinguished between two 'knowledge bases': 'analytical' and 'synthetic', before later adding a third: 'symbolic knowledge'.

According to Asheim and colleagues, 'analytical knowledge' is strongly associated with specialised skills (and associated qualifications and activities) related to rational abstraction, objective reasoning and empirical testing. Due to its cognitive and formally based procedural foundations, analytical knowledge is developed using (widely) recognised and 'legitimate', formalised models and predefined methods, that are framed by systematic and organised structures and codes of conduct (Asheim et al., 2007). This 'type', 'form' or 'mode' of knowledge has close parallels with Gibbons and colleagues' (Gibbons et al., 1994) Mode 1 of knowledge production, which is driven by the application of 'scientific methods' (c.f., the 'science and technology' mode of innovation identified by Jensen et al. (2007)). Firms with an analytical knowledge base tend, therefore, to be more reliant on scientific knowledge and techniques, and often use formal or informal R\&D activities as key inputs to 
the development of their innovative products or processes (Asheim et al., 2007; Gertler and Levitte, 2005). Pharmaceuticals, and the computer-science based parts of the IT industry, are exemplars of industries based on 'analytical knowledge'.

For Asheim and colleagues, a 'synthetic knowledge base' is, by contrast, essentially pragmatic and primarily focused on local problem solving activities; that is, finding a specific solution to a problem. It is similar to the Mode 2 of knowledge production identified by Gibbons et al (1994) and the 'doing, using and interacting mode' identified by Jensen et al (2007). Rather than being based on 'pure', abstract and legitimated 'scientific methods', synthetic knowledge is instead less formalised, more practical and fundamentally solution oriented: it is based essentially on 'know-how', without necessarily being grounded in theoretically informed 'know why' knowledge (Lundvall and Johnson, 1994); tacit knowledge, grounded in experience, is especially prominent. Being focused on the efficacy of local solutions to current problems (Asheim and Gertler, 2005; Gertler and Levitte, 2005) innovation arises from the application of experience, ingenuity and organisational interactions between actors, such as between consultant and client. Typically incremental, innovations reliant on synthetic knowledge are usually incorporated as improvements to, or customisations of, existing products and processes. Exemplars of 'synthetic knowledge' industries are those based on engineering, and especially less formalised engineering, such as construction.

While the 'analytical' and 'synthetic' knowledge bases identified by Asheim and colleagues have close similarities to those previously identified in the innovation literature (e.g., Pavitt, 1984; Gibbons et al., 1994; Jensen et al., 2007), their most novel contribution lies in the identification of 'symbolic knowledge', as a third knowledge 'base'. Symbolic knowledge is transmitted through signs, symbols, images, narratives and sounds, and it is especially relevant to creative and cultural, or 'expressive', industries, such as the media, fashion and advertising. This is because symbolic knowledge concerns expression and emotion, and understanding these, and is more intuitive and (arguably) subjective. Its value, which relates to the ability to stimulate, or manipulate, the emotions of consumers (Martin and Moodysson, 2011), is more obviously socially constructed than is the case with analytical or synthetic knowledge. While the concepts of tacit and codified knowledge can be applied to 'symbolic knowledge', they are arguably less meaningful as languages and symbols are at once both explicit and loaded with hard to convey meanings. Engaging in activities rich in, or heavily dependent upon, symbolic knowledge, such as fashion design, requires the ability to interpret, create or manipulate symbols and languages, but also to persuade others of their 
value (Verganti, 2008, Martin and Moodysson, 2011). Other industries in which symbolic knowledge is highly prominent include advertising, architecture and industrial design consulting (Scott, 1997, 2007); these are industries which shape meanings and desire in the audience's minds (Asheim et al., 2007).

Asheim and colleagues' 'knowledge bases' are ideal types and were not developed specifically with services in mind, but we consider KIBS to be a particularly appropriate setting in which to try to apply this conceptualisation, both conceptually and empirically, because these firms are quintessentially 'knowledge based' - that is knowledge - know what, why, how, who, etc. - is fundamental to what they do. Furthermore, as service providers, there is a close connection, if not an inseparability, between what is provided (the service 'product') and how the service is provided (the service 'process'), with the same 'knowledge base' central to both. In fashion design, for example, the process of designing and developing ideas is intimately related to the designs produced.

\subsection{Applying the SAS knowledge bases to KIBS 'industries'}

We began, therefore, by identifying a selection of six 'knowledge intensive business services' as defined by standard industrial classifications. Those selected were those included in the NESTA study for which we had firm-level data; i.e., accountancy, legal services, architecture and engineering activities, management consulting; IT services and specialist design. For each of these, we reviewed the nature of the activities included within each code by referring to the official definitions of these 'industries' (ONS, 2002; 2009), and reflected on the nature of the knowledge likely to be being utilised. These industry activities are summarised in Table 1, alongside considerations about their knowledge bases. 
Table 1: Industry, summary of activities and inferred knowledge bases

\begin{tabular}{l}
\hline Industry as defined by SIC (UK SIC 2003) \\
\hline Accountancy (74.12): Includes the preparation, \\
auditing and examination of accounts, provision \\
of advice, preparation of tax returns, recording \\
and execution of transactions, representation.
\end{tabular}

Legal services (74.11): Includes provision of legal advice and representation, preparation of legal documents and execution of legal procedures (e.g., conveyancing, probate, etc.)

Architectural and engineering activities (74.2): Includes the provision of architectural services (including design), engineering services (including engineering design which involves applying physical laws and principles of engineering), drafting services, building inspection services and surveying and mapping services.

Consultancy Services (74.14) Includes the provision of advice, guidance, lobbying and operational and strategic assistance to businesses and other organisations.

Software and IT Services $(72.2,72.3,72.4)$ : includes software consultancy, development and supply, including writing, modifying, testing and supporting software; planning, configuring and implementing IT systems that integrate hardware, software and communication technologies; developing webpages; on-site management and operation of clients' IT systems; data processing facilities; and data management activities.

\section{Reflections on the use of knowledge bases}

Synthetic knowledge likely to be significant, with some analytical knowledge also present, especially in forensic accounting. Symbolic knowledge not evident. Limitations of the three SAS knowledge bases also appear - these professions rely on knowledge of laws and procedures, which are not apparent in any of the three SAS knowledge bases.

While synthetic knowledge is likely to be widespread, the sector also includes analytical knowledge, especially in the development and application of engineering design (e.g. structural design), and symbolic knowledge, particularly in the design of buildings with strong visual appeal - i.e., those often designed by 'starchitects' (see Tether et al., 2012).

Likely largely based on synthetic knowledge; some analytical knowledge applied by consultancies applying in 'scientific analysis'. No clear role for symbolic knowledge.

Synthetic knowledge, especially in relation to supporting and integrating IT systems, likely to be widespread, but also with some analytical knowledge, especially among companies specialised in the writing of analytical computer programmes. Symbolic knowledge likely to play a minor role, except among firms developing websites and computer games, which often have or require significant symbolic content.

\begin{tabular}{|c|c|}
\hline $\begin{array}{l}\text { Specialist design ( } 74.87 / 2 \text { ): including fashion } \\
\text { design; industrial design (i.e. creating and } \\
\text { developing designs and specifications that } \\
\text { optimise the use, value and appearance of } \\
\text { products); activities of graphic designers; } \\
\text { activities of interior decorators }\end{array}$ & $\begin{array}{l}\text { Symbolic knowledge likely to be particularly } \\
\text { significant here, especially in fashion and } \\
\text { industrial design. Analytical knowledge also } \\
\text { present among firms applying 'technical design'. } \\
\text { Synthetic knowledge likely to be widespread, } \\
\text { but often 'back-stage' rather than 'front-stage'. }\end{array}$ \\
\hline
\end{tabular}

The analysis is based on SIC 2003 because these codes were used in the NESTA report. For all the industries except Software and IT Services, there is a one to one mapping to the present, SIC 2007 codes. 
This exercise revealed three things: first that synthetic knowledge appears to be the most widespread, being utilised in all of the industries. Second that most industries utilise at least two of the knowledge bases, with all three being used in architecture and engineering activities, IT services and specialist design, albeit to different degrees; this indicates there is not a one-to-one mapping of 'knowledge bases' and SIC defined industries. Third, a 'knowledge base' associated with understanding, applying and interpreting laws and regulations, which is most apparent in legal and accountancy services (and arguably central to these, with entrants to these professions required to pass examinations on this knowledge), is not well catered for by any of the SAS knowledge bases. This indicates the typology is incomplete.

To explore these issues further, we sought to identify knowledge bases at the firm level, rather than at the level of industries. This is appropriate given that the typology refers to micro-level (organisational and inter-organisational) social systems (Manniche, 2012) and knowledge bases are closely related to the nature of a firm's core activities (e.g. Martin and Moodysson, 2011). However, a firm level analysis raises the question whether firms tend to specialise in one knowledge base, or engage in two or more simultaneously. Firms may specialise in one, or be ambidextrous, simultaneously engaging in two or more. It is not immediately obvious which of these approaches is optimal. Specialisation is likely to lead to a clear sense of identity and purpose, but ambidexterity may enable firms to execute more complex projects without the coordination costs of working with other providers. Note, however, that enduring formal and informal partnerships between KIBS firms with different knowledge bases are commonplace, which reduces the coordination costs for consortia formed of specialised firms.

There is also the empirical challenge as to how to identify and measure knowledge bases. Hitherto, Asheim and colleagues' model has mainly been applied empirically through in-depth case studies (e.g., Strambach and Dieterich, 2011; Liu et al, 2013), or with regions or industries as the level of analysis (e.g. Asheim \& Coenen, 2005; Moodysson et al., 2008; Coenen \& Moodysson, 2009); very few quantitative, firm-level studies have sought to measure knowledge bases empirically; two exceptions being Martin (2012) and Tether et al (2012), both of which use occupations, and occupational data, to infer the knowledge base(s) being utilised.

In this paper we use web-sites to identify 'knowledge bases'. The process, which is described more fully in Section 3.2 below, is akin to a doctor diagnosing a disease. The doctor looks for symptoms, none of which may individually indicate, or confirm, the disease, 
but which, when taken together, support a diagnosis. In particular, because 'analytical knowledge' is fundamentally based on the application of rigorous, scientific methods and focused on 'analysis' and 'analytics', we looked for evidence of this through the use of words and phrases (and, in the manual analysis, graphics) which indicated the firm focused on this. Aside from 'analysis' and 'analytics', key words included 'science' or 'scientific', 'examine', 'evaluate' and 'research'. Scientific 'models' were sometimes referred to, and the work was sometimes undertaken in a 'laboratory'; outputs were often in the form of reports. Meanwhile, because 'synthetic knowledge' is fundamentally oriented to the provision of solutions, which are primarily pragmatic, rather than optimal, we sought evidence that the firm engaged in solving field problems, through practical means. This was particularly apparent when firms placed an emphasis on their problem solving capabilities, usually with an emphasis on prior experience, sometimes supported by detailed case studies which indicate they had solved clients' problems. This work, which is typically highly interactive, is often reported as having been undertaken with clients (as opposed to for clients), and is often undertaken at clients' premises. Lastly, because 'symbolic knowledge' is closely associated with emotions and forms of expression, we searched for evidence through words, phrases (and, in the manual analysis, associated graphics) that the business engaged with these. An emphasis on 'art', and artistic activities such as 'designing' were, for example, key signals, as was 'inspiration', and the use of the word 'studio', as opposed to 'office', to describe the workplace.

Conceptual distinctions are interesting, but to be useful two things are required. First, a reasonably robust method needs to be developed that can apply the distinctions to empirical data. In other words, and in this context, how can we tell if Firm $\mathrm{X}$ has an analytical, synthetic or symbolic knowledge base, or some combination of these? Second, the applied distinction needs to be useful in explaining, or help to explain, something of significance. In other words, why does it matter that Firm $\mathrm{X}$ has a different knowledge base from Firm Y? With regard to the first challenge, this paper develops a methodology by which the primary knowledge base of each KIBS firm can be identified, a methodology that could potentially be extended to firms in other sectors. With regard to the second, we anticipate that firms with different primary knowledge bases will have different characteristics and will behave differently with respect to innovation. In particular, we anticipate that:

- $\quad$ KIBS with an analytical knowledge base will be more likely to be large while those with a symbolic knowledge base will tend to be small. This is because it is easier to 
scale a business based on analytical knowledge and more difficult to scale one based on symbolic knowledge. Synthetic knowledge is in between.

- $\quad$ KIBS with a symbolic knowledge base are more likely to be located centrally, in large metropolitan areas (in order to take advantage of "buzz" and specialist labour markets (Scott, 1997; Storper and Venables, 2004; Shearmur and Doloreux, 2008), while those with a synthetic knowledge base are likely to be more dispersed (to be close to their clients). KIBS with an analytical knowledge base are able to disperse, but may be more specialised, and therefore may locate centrally (Tether et al., 2012).

- $\quad$ KIBS with an analytical knowledge base are the most likely to invest in R\&D, while those with a symbolic knowledge base are the least likely to do this.

- $\quad$ KIBS with an analytical knowledge base are the most likely to introduce innovations, and especially 'product innovations', because their services are more likely to be discrete, or 'packaged', rather than highly customised or bespoke projects, as is the case with the other knowledge bases. This makes 'product innovations' more evident in activities based on analytical knowledge.

\section{Methods and measures}

\subsection{Data-source and sample}

Our empirical starting point is a dataset, compiled by OMB Research (a survey company) on behalf of a NESTA study team led by Stephen Roper (Roper et al., 2009; Love et al, 2011), ${ }^{5}$ which sought to measure 'sectoral innovation capability' in nine sectors of the UK economy. The sectors were defined by Standard Industrial Classification (SIC) codes. For the reasons given previously, we confine our attention to three KIBS sectors: 'architecture (and engineering consultancy)'; 'specialist design', and 'software and IT services' for which: 1. The SAS model appeared to be the most appropriate, and 2. Which appear to utilise different knowledge bases.

The original telephone based survey was undertaken in the summer of 2009 , and gathered information on: 1) background characteristics, e.g., firm size, age, etc.; 2) innovation related behaviours and investments, including investments in R\&D, design,

\footnotetext{
${ }^{5}$ NESTA is the UK's National Endowment for Science Technology and the Arts. It is an innovation charity whose mission is to help people and organisations bring ideas to life. As part of its activities, NESTA both undertakes and commissions research.
} 
information technologies and branding/reputation; 3) innovation output and performance, using measures based on the OECD's Oslo Manual (2005) and European Community Innovation Surveys (CIS). One feature of this dataset which makes it more difficult to use is that the questionnaire was customised for each 'sector', such that a standard set of questions was not asked to all firms.

Following piloting in early June 2009, the survey was undertaken using Computer Aided Telephone Interviewing (CATI) in the late summer of 2009. The target population was all firms in the specified sectors, divided into three size-bands by employment: [Small] 5 to 19; [Medium] 20 to 99; and [Large] 100 or more employees. Furthermore, only 'established firms' that had been in business for at least 3 years were included. A random sample of firms was drawn for each sector-size cell using data provided by a commercial database provider. Telephone interviews were then conducted with the managing director, a member of the senior management team, or the individual with lead responsibility for new product or service development within the firm. If a firm declined to participate a new firm was drawn at random from the appropriate cell until the quota for each sector-size cell had been reached. The main difficulty encountered was securing responses from large companies, especially in the specialist design sector, in which there are few large firms. The overall response rate was $15 \%$, which is reasonable for surveys of this type. The analysis in this paper treats the dataset as a simple, un-weighted sample.

For all but 40 of the initial sample of 591 firms, ${ }^{6}$ we were also given their names and addresses (including postcodes), and we used this information to classify the firms by their locations. Firms were classified as being located in: 1. inner London (as defined by the Office for National Statistics); $;^{7}$. elsewhere in the London Metropolitan Area; 3. in another Metropolitan Area (such as Birmingham, Leeds or Manchester); 4. in a smaller, nonmetropolitan city; or 5. in a town or rural area (i.e., places not included above). Except for 'Inner London', the locations and locational categories were defined by ESPON (2007).

\subsection{Identifying 'knowledge bases'}

Because the dataset contains no explicit information on the knowledge base(s) central to each firm, we had to gather information related to this from secondary sources. In particular, using

\footnotetext{
${ }^{6}$ The 40 firms for which names and addresses were not provided were those that refused permission for their details to be shared with the academic study team.

${ }^{7}$ See http://www.ons.gov.uk/ons/guide-method/geography/beginner-s-guide/eurostat/london/index.html
} 
the company names and addresses, we first searched for firms in the Financial Analysis Made Easy (FAME) database of company accounts, which, among other things, provides links to company websites. Websites were found for all but 46 of the firms.

The search of FAME and companies' websites revealed interesting information. In particular, we found that many firms were not (primarily) engaged in the activities that we had expected them to be active in according to their SIC classification. Especially among the firms classified as being engaged in 'architecture (and engineering consultancy)' we found that over half the sample were, or appeared to be, primarily manufacturing firms. We could tell this by their emphasis on making and selling products, as opposed to providing services (such as consulting). Other firms were apparently contractors. Indeed, of the 206 'architecture (and engineering consultancy)' firms for which names and addresses were provided, and websites found, less than half (88: 43\%) were considered by us to be primarily engaged in consultancy and other professional services; that is KIBS activities. This problem also existed, albeit to a lesser extent, for firms engaged in 'computer software and IT consulting' and 'specialist design', among which we found (for example) several retailers, and a few product manufacturers (e.g., packaged software, IT equipment). Overall, we considered that 143 of the $176(81 \%)$ software and IT consulting firms and 131 of the $169(77 \%)$ of the 'specialist design firms' for which names were provided and websites found were KIBS. While most cases were obvious, it was not always easy to determine whether or not a firm should be regarded as a KIBS firm. ${ }^{8}$ Overall, we judged that 362 of the sample of 551 firms (for which names were provided) were KIBS firms (Table 2).

Table 2: The initial sample and analysed sample of KIBS firms

\begin{tabular}{lcccc}
\hline Sector & Initial sample & $\begin{array}{c}\text { Names not } \\
\text { provided }\end{array}$ & $\begin{array}{c}\text { Excluded as } \\
\text { manufacturing } \\
\text { or other non- } \\
\text { KIBS activity }\end{array}$ & $\begin{array}{c}\text { Analysed } \\
\text { sample of KIBS } \\
\text { firms }\end{array}$ \\
\hline $\begin{array}{l}\text { Architecture and Engineering } \\
\quad \text { Consultancy }\end{array}$ & 217 & 18 & 111 & 88 \\
Software and IT Services & 189 & 19 & 27 & 143 \\
Specialist Design & 185 & 26 & 28 & 131 \\
\hline Combined Sample & 591 & 63 & 166 & 362 \\
\hline
\end{tabular}

\footnotetext{
${ }^{8}$ It is also possible that some of the firms were, at the time of the original survey, KIBS providers but have since changed, becoming for example manufacturing businesses in accordance with Bullock's 'soft to hard' model (Bullock, 1983). However, based on the available evidence, we think it is unlikely that the vast majority of these 'incorrectly classified' firms underwent such transformations.
} 
After refining the sample to 362 firms we reviewed their websites, aiming to identify the 'knowledge base(s)' central to each firm. Websites can be considered public sources of information that provide information pertaining to a firm's activities, strategies and identity (Scott and Lane, 2000, Gioia and Thomas, 1996), all of which are related to its knowledge base(s). Studies on corporate communications by means of websites have emphasised the 'controllable' nature of this channel as a way to inform and communicate with customers, potential clients and other stakeholders (Balmer and Greyser, 2002; Bronn and Martisen, 2006). The information presented is generally managed by firm's marketing department or managers, and tends to reflect the organisation's 'communicated identity' (Balmer and Greyser, 2002). As such, we must appreciate that websites will highlight those aspects of the firm that it wishes to emphasise, with other aspects downplayed or hidden (Bronn and Martisen, 2006); websites do not provide an unbiased account of the essence or 'substance' of the firm (Alvesson, 1990). In other words, they reflect the firm's 'communication identity' rather than its 'true identify' (Alvesson, 1990). This suggests that activities associated with the firm's core services, and especially those that are 'front of house', and central to its value proposition, are likely to be highlighted, while those that are not differentiators, which are related to back office activities, and only associated with execution, are likely to be less prominent.

Although less than ideal, we consider that in knowledge-based services these limitations are not catastrophic, because of the close connection between what is provided and the process of provision, including, crucially, the nature of the knowledge base developed and applied. Consequently, while bearing these limitations in mind, we subjected the websites to content analysis, which is a technique for making inferences by systematically identifying characteristics of messages (King, 2004; Neuendorf, 2002). Through the analysis of patterns in text, content analysis of websites has previously been used as a way of identifying the raison d'être of a company (Stemler, 2001).

Specifically, we used an a priori approach to content analysis (Neuendorf, 2002), which is driven by the use of pre-defined, theoretically-based codes and categories (Stemler, 2001). In our case, the codes and categories were those initially developed from Asheim and colleagues' conceptual typology and applied to architecture and engineering consultancy activities by Tether et al. (2012). Specifically, the coding reflected: (1) nature of the knowledge used: codified or tacit; (2) the activities likely to be associated with new knowledge production; (3) forms of innovation and solutions provided; (4) means of sharing and diffusing knowledge; and (5) the identification of exemplar industries. 
Then, focusing primarily on the 'Home', 'About Us', 'Our Business', 'Services', 'What We Do', 'Solutions', 'Experience', 'Portfolio', 'People' and 'Philosophy' webpages (or sections thereof), and using both human and computer-based methods, we searched for, extracted and coded textual content related to company information, organisational activities, work processes and the firm's core products and/or services, especially as these related to the key features of the three 'knowledge bases' central to this study. Specifically, because firms with an analytical knowledge base tend to rely on scientific knowledge and research, we searched for content that suggested the use of rational models and frameworks, and the codification of information into documented reports (including patents) (Asheim and Coenen, 2005). To identify a synthetic knowledge base, we searched for information that suggested a focus on the application of know-how and practical, (ad hoc) problem solving, such as through the provision of 'solutions', and/or frequent references to co-operation and similar behaviours, such as face-to-face interactions. With regard to a symbolic knowledge base, we looked for content suggesting a creative and artistic orientation (e.g., that work is undertaken in a 'studio' rather than in an office or laboratory) and for an emphasis on the production of symbolic and cultural artefacts.

Content analysis is especially useful for the identification and analysis of different clusters of text, as it provides an organised and methodical way of coding and interpreting the available textual information. We undertook the content analysis in four steps:

Step 1 involved a manual analysis of each firm's webpages, and the subsequent classification of the firm's as having an 'analytical', 'synthetic' or 'symbolic' knowledge base, or some combination thereof. In order to ensure consistency in the interpretations of the data, two researchers (both authors) participated in the analysis and independently coded webpages. This involved an initial discussion, which agreed the coding framework; we then independently analysed and coded the websites of a sample of 30 randomly drawn firms. This exercise achieved a high level of agreement, with identical coding for 24 of the 30 cases and disagreement on 6 (i.e., $80 \%$ inter-rater reliability). Disagreements were then discussed, after which another set of 30 firms were randomly drawn from the dataset and these were again classified independently. This time inter-rater reliability was 87\% (agreement on 26; disagreement on 4). Subsequently, one researcher - the first author - manually classified the rest of the dataset, discussing and resolving any 'problem cases' with the second researcher.

Four aspects of this process are notable. First, we found it relatively easy to identify firms based apparently on 'analytical' or 'symbolic knowledge' - and to differentiate the two - while identifying firms based apparently on 'synthetic knowledge' was more difficult. This 
was because firms we perceived to have an analytical knowledge base presented themselves very differently from those we perceived to have a symbolic knowledge base. 'Symbolic knowledge based firms', as exemplified by creative design agencies, typically present themselves through very colourful, graphics rich, and fun websites. Key people are usually named, but often only by their first (or given) name, indicating a very informal approach. By contrast, primarily 'analytical firms' tend to emphasise what they do (as a firm), and names of key individuals are very often not provided. When they are, full names are typically provided, in a formal fashion, often with supporting credentials, such as degrees from specific universities, or membership of important institutions. 'Synthetic firms' tend to be closer to 'analytical firms' in presentation, but with greater emphasis on problem solving and experience. Second, very rarely did firms appear to be engaged in activities underpinned by both analytical and a symbolic knowledge. Third, were disagreements arose these all concerned the extent of 'synthetic knowledge'. Fourth, most firms appeared to be specialised in one of these knowledge bases. Indeed, only 47 of the 362 firms (13\%) were initially coded to more than one knowledge base, and most of these to 'analytical' and 'synthetic'. As most of the firms in this study are small, with fewer than 100 employees, this specialisation by knowledge base was not unexpected.

Due to these challenges, we decided to try to identify the primary knowledge base of each firm, rather than look for evidence of the presence of each knowledge base (and the relative strength of these). In practice this meant that firms which were not clearly identifiable as having either an analytical or a symbolic knowledge base were more likely to be identified as having a primarily 'synthetic knowledge base'. Furthermore, of the 47 firms initially classified as having multiple knowledge bases, 31 were eventually classified as 'synthetic', 11 as 'analytical', and 5 as 'symbolic'. We accept that identifying firms only by their (apparently) primary knowledge base is a limitation of this work.

Step 2 involved an automated coding of the data. Aware that: 1. most of the dataset had only been coded by a single researcher; and 2. that human coding is prone to error due to fatigue and other factors, we undertook a computer-based analysis of the data. This involved using the NCapture tool in the NVIVO 10 qualitative software package, to capture the full textual information from the websites of the 362 KIBS firms. NVIVO was used to identify the 800 most frequently occurring words on the websites. ${ }^{9}$ Both researchers then

\footnotetext{
${ }^{9}$ Strictly 'words' are those with same four letter stem - e.g., inno* - includes innovate, innovation, innovations, innovator, etc
} 
independently reviewed these words, selecting those they felt associated most closely with each of the three knowledge bases. After some discussion, this exercise resulted in an agreed list of 15 words that we considered associated with 'symbolic knowledge' (i.e., insight, idea, inspiration, art, studio, emotion, cultural, illustrator, feel, music, brand, identity, love, designer, and creativity) and 16 which we associated with 'analytical knowledge' (i.e., data, tools, optimisation, models, analytics, computing, analysis, measurement, simulation, laboratory, evaluation, research, science, accurate, report, and tests). Frustratingly, the same exercise did not yield a set of words, either in sufficient number or in sufficient frequency, that could be associated with 'synthetic knowledge' (i.e., words such as 'experience' and 'solutions' did not arise in sufficient number or frequency). Possibly, this relates to the more tacit and less explicit nature of 'synthetic knowledge', such that it is more difficult to define this knowledge base through associated terms. We then ran a word search query in NVIVO 10 to count the occurrences of these 31 'analytical' and 'symbolic' words in each firm's website. This provided a dataset of word occurrences by firm.

Step 3 was a validation exercise. Since we are inferring that the frequent appearance of certain words indicates an orientation to a knowledge base, we assume that 'symbolic words' will occur with relatively high frequency in the websites of firms with a symbolic knowledge base, while 'analytical words' will occur with relatively high frequency in the websites of firms with an analytical knowledge base. A challenge is that the content of firms' websites varies enormously, both in the number of words used and in their frequency. We found initially that both 'symbolic' and 'analytical' words tend to co-occur on websites, albeit with very different frequencies. To overcome this, we excluded from the analysis words that occurred with low frequency on any particular website (c.f., Criscuolo et al., 2007). ${ }^{10}$ Initially, we instituted the rule that words occurring three or fewer times on a company's website were omitted. This led to the exclusion of 84 firms ( $23 \%$ of the firms) on whose websites none of the 31 words occurred four or more times; but applying this cut off still left both 'analytical' and 'symbolic' words co-occurring on individual firm's websites. We then raised the threshold, eventually requiring words to occur at least six times; this excluded 112 firms ( $31 \%$ of the sample) from the analysis. This 'six or more' rule was effective is separating the occurrence of 'analytical' and 'symbolic' words on most firms' websites. Interestingly most of the 112 firms excluded by this rule had been manually coded as having a 'synthetic

\footnotetext{
${ }^{10}$ Criscuolo et al. (2007) applied co-word analysis to a company's "yellow pages" of individual consultant's expertise. To be included in their analysis, they required all words and phrases to occur more than 10 times.
} 
knowledge base'. This indicates that while we had been unsuccessful in identifying words that could be strongly associated with a 'synthetic knowledge base', at least these firms (as manually classified) rarely used 'analytical' or 'symbolic' words with a high frequency.

To test the separation, we then subjected the remaining 250 firms to cluster analysis, using the UCINET 6 software package (Borgatti et al., 2002). This identifies clusters based on the co-occurrence of words on the firms' webpages. Specifically, we used a social network analysis technique called the dual-projection approach (Everett and Borgatti, 2013) which permits a faithful reconstruction of the dataset without any loss of information. UCINET can cluster the words into two or more 'factions' at the user's discretion. Our analysis found that (1) when asked to cluster the information into two factions, the programme 'correctly' separated the 'symbolic words' from the 'analytical words', and (2) regardless the number of factions selected (two, three or four), the symbolic words very largely remained in one faction, while the 'analytical' words tended to splinter into multiple factions. ${ }^{11}$ We decided to keep the aggregation into two factions, considering this achieved a very high fit (0.972) which reflects the almost perfect partition of the words into two factions: 'analytical' and 'symbolic' words. With the division of the words into two groups we were able to automate the identification of firms associated with each group, thereby generating another (softwarebased) classification of the firms by knowledge base.

Step 4 involved comparing our initial manual classification of each firm's knowledge base(s) with the computer-based classification outlined above. Considering only the cases where firms were manually classified as either 'analytical' or 'symbolic', we found an $85 \%$ level of agreement with the computer-based classification. We then reviewed all the 'disagreements' between the computer's classification and our initial manual classifications, and this led to some changes. Overall, we consider that manual coding is more reliable but that the computer-based coding provides a valuable second opinion. Table 3 provides our final classification of the firms by their primary 'knowledge base'.

Table 4 cross-tabulates the 'knowledge-base' classification with the (SIC) sectors in which the firms were active. This shows that while there is clear variation by sector - e.g., specialist design firms are mainly in the 'symbolic' category, and software and IT consulting firms are predominantly 'synthetic' and 'analytical', there is also considerable variation within sectors, most notably among the 'architecture and engineering consulting' firms. In

\footnotetext{
${ }^{11}$ The results of this exercise are available on request.
} 
other words, as anticipated, there is not a one-to-one mapping between knowledge bases and SIC defined industries.

Table 3: Classification of firms by primary 'knowledge base'

\begin{tabular}{lccc}
\hline & $\begin{array}{c}\text { Initial manual } \\
\text { coding }\end{array}$ & $\begin{array}{c}\text { Computer-based } \\
\text { coding }\end{array}$ & Final classification \\
\hline Analytical & 62 & 96 & 73 \\
Synthetic & 138 & 0 & 169 \\
Symbolic & 115 & 105 & 120 \\
More than One & 47 & 0 & 0 \\
Not classified $(\#)$ & 0 & 112 & 0 \\
\hline Total sample & 362 & 362 & 362 \\
\hline
\end{tabular}

\# These were the firms for which none of the specified words occurred at least 6 times

Table 4: Primary 'knowledge bases' by sector among KIBS

\begin{tabular}{lcccc}
\hline & All & Analytical & Synthetic & Symbolic \\
\hline Whole sample & 362 & 73 & 169 & 120 \\
\hline Architecture and Engineering Consultancy & 88 & 28 & 51 & 9 \\
Software and IT services & 143 & 44 & 96 & 3 \\
Specialist design & 131 & 1 & 22 & 108 \\
\hline
\end{tabular}

\section{Relating knowledge bases to differences in firm characteristics and behaviours}

Having arrived at this classification, the next question is whether or not it matters. For example, does it help to 'explain' differences in the characteristics of firms or the ways in which they behave? The descriptive statistics shown in Table 5 reveals some other interesting similarities and differences between the sets of firms, including:

- $\quad$ That KIBS with a 'symbolic knowledge base' tend to be small; three quarters having fewer than 20 employees. By contrast, over a third of the 'analytical firms' are large, with over 100 employees. This difference, which we had anticipated, is likely to reflect fundamental differences in the ability to scale these different types of business. 'Symbolic knowledge' is often highly personal and associated with an individual or small group, which makes it difficult (but not impossible) to undertake at scale without diluting the identity of the business. 'Analytical knowledge', by contrast is impersonal, 
which makes it easier to scale, and therefore easier to expand a business constructed around this knowledge base. Synthetic knowledge is in-between.

- With regard to location, we find KIBS categorised as having each of the three primary knowledge bases are located in each of the locational categories, but there is some evidence that those with a symbolic knowledge base are more likely to locate in inner London, while those with a synthetic knowledge base are less likely to be located there; they are relatively more likely to be located in smaller towns and rural areas. Firms primarily based on analytical knowledge are relatively more likely to be located in cities, outside of the main metropolitan areas.

- In all three categories the share of graduates tends to be high, with graduates comprising over half the workforce in three-quarters of the 'analytical firms', in $70 \%$ of the 'symbolic firms' and over half of the 'synthetic firms'. ${ }^{12}$ It is notable, however, that graduates comprise a minority of the workforce in some KIBS firms, and that this share tends to be greater among the practically oriented 'synthetic firms'.

- Also notable is that the firms in each category varied greatly in their propensity to engage in different activities. For instance, $42 \%$ of the 'analytical firms' reported investing in $R \& D$. While lower than anticipated, this is substantially higher than the share among 'synthetic firms' (28\%), and three times the share among 'symbolic firms' (14\%). Meanwhile, all three firm types were more likely to invest in design than $\mathrm{R} \& \mathrm{D},{ }^{13}$ with the propensity to invest in branding and reputation being higher still, and most widespread among the symbolic firms. We will analyse these differences further shortly, using regression techniques.

- The propensity to innovate - as measured by the introduction of new or significantly changed products or services, or new or significantly changed processes or $\operatorname{organisational~structures}^{14}$ - was, as anticipated, highest among the 'analytical firms'. Meanwhile the propensity to innovate was, as anticipated, lowest among the 'symbolic firms'. We examine these differences further in the section below.

\footnotetext{
${ }^{12}$ Note that in only $13 \%$ of the miscoded 'manufacturing firms' do graduates comprise over half the workforce.

${ }^{13}$ The firms were asked: "aside from any R\&D you've just mentioned, has your firm invested in the design of new or improved products or services / products / services over the last year?"

${ }^{14} \mathrm{We}$ combine process and organisational innovations because these are often difficult to disentangle in service businesses (Hipp 2000; Preissl, 2000). With this modification of combining process and organisational innovations, these are the basic measures of innovation that are laid out in the OECD's Oslo Manual (2005) and which are widely implemented in the (European) Community Innovation Surveys.
} 
Table 5: Descriptive statistics

\begin{tabular}{|c|c|c|c|c|c|}
\hline \multirow{2}{*}{ Variables } & \multicolumn{3}{|c|}{ KIBS - final classification } & \multicolumn{2}{|c|}{ Non-KIBS } \\
\hline & Analytical & Symbolic & Synthetic & Manuf. & Others \\
\hline Firms (number of observations) & 73 & 120 & 169 & 134 & 32 \\
\hline Sector $=$ "Architecture \& Eng. Consultancy" & $38 \%$ & $8 \%$ & $30 \%$ & $80 \%$ & $13 \%$ \\
\hline Sector $=$ "Specialist design" & $1 \%$ & $90 \%$ & $13 \%$ & $10 \%$ & $44 \%$ \\
\hline Sector = "Software and IT Services" & $60 \%$ & $3 \%$ & $57 \%$ & $10 \%$ & $44 \%$ \\
\hline Location $=$ Inner London & $14 \%$ & $18 \%$ & $11 \%$ & $1 \%$ & $9 \%$ \\
\hline Location $=$ Outer London Metropolitan Area & $20 \%$ & $21 \%$ & $21 \%$ & $23 \%$ & $16 \%$ \\
\hline Location $=$ Other Metropolitan Areas & $30 \%$ & $32 \%$ & $36 \%$ & $39 \%$ & $50 \%$ \\
\hline Location $=$ Other, smaller cities & $27 \%$ & $19 \%$ & $18 \%$ & $23 \%$ & $13 \%$ \\
\hline Location $=$ Towns and rural areas & $8 \%$ & $10 \%$ & $15 \%$ & $14 \%$ & $12 \%$ \\
\hline Size $=$ Small firms (5-19 employees) & $32 \%$ & $76 \%$ & $42 \%$ & $31 \%$ & $44 \%$ \\
\hline Size $=$ Medium firms (20-99 employees $)$ & $32 \%$ & $23 \%$ & $34 \%$ & $34 \%$ & $34 \%$ \\
\hline Size $=$ Large firms $(100+$ employees $)$ & $37 \%$ & $2 \%$ & $24 \%$ & $34 \%$ & $22 \%$ \\
\hline Age $=$ Young firms $($ less than 10 years old) & $29 \%$ & $28 \%$ & $19 \%$ & $16 \%$ & $22 \%$ \\
\hline Graduates in workforce $=$ none to $5 \%$ & $1 \%$ & $7 \%$ & $10 \%$ & $41 \%$ & $16 \%$ \\
\hline Graduates in workforce $=6-20 \%$ & $5 \%$ & $4 \%$ & $15 \%$ & $32 \%$ & $6 \%$ \\
\hline Graduates in workforce $=21-50 \%$ & $16 \%$ & $19 \%$ & $21 \%$ & $13 \%$ & $28 \%$ \\
\hline Graduates in workforce $=$ over $50 \%$ & $77 \%$ & $70 \%$ & $54 \%$ & $13 \%$ & $50 \%$ \\
\hline Engaged in Research \& Development? & $42 \%$ & $14 \%$ & $28 \%$ & $37 \%$ & $16 \%$ \\
\hline Median R\&D/emp. spend (when $>£ 0$ ) & $£ 2,500$ & $£ 1,430$ & $£ 7,570$ & $£ 2,000$ & $£ 2,000$ \\
\hline Engaged in design activities? & $52 \%$ & $25 \%$ & $41 \%$ & $41 \%$ & $41 \%$ \\
\hline Median design/emp. spend (when $>£ 0$ ) & $£ 2,500$ & $£ 1,040$ & $£ 3,950$ & $£ 1,250$ & $£ 830$ \\
\hline Invested in IT? & $47 \%$ & $65 \%$ & $64 \%$ & $55 \%$ & $53 \%$ \\
\hline Median IT/emp. spend (when $>£ 0$ ) & $£ 975$ & $£ 1,000$ & $£ 835$ & $£ 509$ & $£ 660$ \\
\hline Invested in reputation or branding? & $53 \%$ & $63 \%$ & $48 \%$ & $45 \%$ & $63 \%$ \\
\hline- median brand/emp. spend $($ when $>£ 0)$ & $£ 630$ & $£ 1,200$ & $£ 835$ & $£ 400$ & $£ 720$ \\
\hline Introduced product/services innovations & $75 \%$ & $48 \%$ & $59 \%$ & $56 \%$ & $63 \%$ \\
\hline Introduced process \&/ or org innovations & $68 \%$ & $50 \%$ & $53 \%$ & $58 \%$ & $56 \%$ \\
\hline
\end{tabular}




\subsection{Relating knowledge bases to investment and innovation behaviours}

Table 5 showed that firms with different 'knowledge-bases' appear to vary in their propensity to invest in different activities such as $\mathrm{R} \& \mathrm{D}$ and design, as well as in their propensities to innovate. We now test more formally whether our categorisation can add to understanding. ${ }^{15}$

In relation to $\mathrm{R} \& \mathrm{D}$ and design, questions about investing in these activities were asked together, so we estimate a multinomial logistic regression with four possible outcomes: 1 . the firm invested in neither of these (188 cases); 2. the firm invested in R\&D but not design (36 cases); 3. the firm invested in design but not R\&D (78 cases); and 4. the firm invested in both R\&D and design (60 cases). We use 'neither' as the reference case, and include firm size (ln employment), sector (dummy variables for two of the three sectors), location (a set of four dummies, with metropolitan areas other than London as the reference case) and firm age (a dummy variable for 'young' firms founded in the last 10 years) in the first model. After this, we added two dummy variables in the second model: one for firms identified as having a primarily 'analytical knowledge base'; the other for firms identified as having a primarily 'symbolic knowledge base'. Firms with a primarily 'synthetic knowledge base' serve as the reference category. The results are reported in Table 6 .

We find that after controlling for size, age, sector and location, firms with a primarily 'symbolic knowledge base' are significantly less likely to simultaneously engage in both R\&D and design than 'synthetic firms'. Meanwhile, firms with a primarily 'analytical knowledge base' are more likely to engage in both R\&D and design at $11 \%$ significance. Also notable is that larger KIBS are (as expected) more likely to engage in R\&D (and both R\&D and design), but not design on its own. Meanwhile architecture and engineering consultancy firms were significantly less likely to engage in these activities. The only locational effects found were unexpected: that (1) KIBS located in Inner London were less likely to engage in design only (but not design and R\&D), and (2) that KIBS located in nonmetropolitan cities were more likely to engage in design (but not design and R\&D).

\footnotetext{
${ }^{15}$ We undertook a similar exercise using binary logistic regressions with regard to investing in branding (and reputation), the results of which we do not include because of space restrictions. Although the overall model is rather weak, investing in branding is strongly associated with firm size and with the 'specialist design' sector, prior to the introduction of the knowledge types variables. After their introduction, 'analytical firms' are not found to differ significantly, but there is evidence that symbolic firms are more likely to invest in branding (and reputation). Similar models for investing in IT proved very weak, with or without the new variables.
} 
Table 6: Multinomial logistic regressions for engaging in $R \& D$, design or both

\begin{tabular}{|c|c|c|c|c|c|c|}
\hline & \multicolumn{3}{|c|}{ Model 1: Excludes knowledge bases } & \multicolumn{3}{|c|}{ Model 2 Includes knowledge bases } \\
\hline & $\begin{array}{l}\text { R\&D Only } \\
\text { B (S.E) }\end{array}$ & $\begin{array}{l}\text { Design } \\
\text { Only } \\
\text { B (S.E) }\end{array}$ & $\begin{array}{l}\text { Both } \\
\text { B (S.E) }\end{array}$ & $\begin{array}{l}\text { R\&D } \\
\text { Only } \\
\text { B (S.E) }\end{array}$ & $\begin{array}{l}\text { Design } \\
\text { Only } \\
\text { B (S.E) }\end{array}$ & $\begin{array}{l}\text { Both } \\
\text { B (S.E) }\end{array}$ \\
\hline Constant & $-2.038 * * *$ & -0.514 & $-1.927 * * *$ & $-2.101 * * *$ & -0.541 & $-1.865 * * *$ \\
\hline Size (Ln_Emp) & $\begin{array}{l}0.265 * * \\
(0.128)\end{array}$ & $\begin{array}{c}0.113 \\
(0.110)\end{array}$ & $\begin{array}{l}0.338 * * * \\
(0.106)\end{array}$ & $\begin{array}{l}0.245^{*} \\
(0.132)\end{array}$ & $\begin{array}{l}0.099 \\
(0.112)\end{array}$ & $\begin{array}{l}0.271 * * \\
(0.107)\end{array}$ \\
\hline Young firm (D) & $0.771 *$ & 0.483 & $1.030 * * *$ & $0.731 *$ & 0.462 & $0.916^{* *}$ \\
\hline S_ArchEng (D) & $-1.081 * *$ & $-1.275 * * *$ & $-1.025 * *$ & $-1.097 * *$ & $-1.270 * * *$ & $-0.953 * *$ \\
\hline S_Design (D) & $-1.062 * *$ & $-1.066 * * *$ & $-1.068 * * *$ & -1.201 & $-1.132 *$ & 0.073 \\
\hline L_Inner London (D) & -0.642 & $-1.784 * * *$ & -0.439 & -0.649 & $-1.776 * * *$ & -0.406 \\
\hline L_Outer London (D) & -0.045 & -0.419 & 0.145 & -0.030 & -0.400 & 0.169 \\
\hline L_Other Cities (D) & 0.553 & $0.933 * *$ & 0.399 & 0.520 & $0.913 * *$ & 0.281 \\
\hline L_Towns/Rural (D) & 0.375 & 0.040 & 0.390 & 0.396 & 0.050 & 0.408 \\
\hline KB_Analytical (D) & Not Incl. & Not Incl. & Not Incl. & 0.419 & 0.221 & $0.641^{(11 \%)}$ \\
\hline KB_Symbolic (D) & Not Incl. & Not Incl. & Not Incl. & 0.310 & 0.154 & $-1.416^{* *}$ \\
\hline N. & & 362 & & & 362 & \\
\hline Model Chi-square & & $64.7 * * *$ & & & $74.6 * * *$ & \\
\hline$-2 \mathrm{LL}$ & & 708.3 & & & 723.2 & \\
\hline McFadden pseudo $\mathrm{R}^{2}$ & & 0.075 & & & 0.086 & \\
\hline
\end{tabular}

188 firms engaged in neither R\&D nor design (reference case); 36 only in R\&D, 78 only in design, and 60 in both R\&D and design. (D) indicates a dummy variable.

$* * *$ significant at $1 \% ; * *$ significant at $5 \% ; *$ significant at $10 \%$.

We undertook the same exercise with regard to the introduction of innovations of different types (see Table 7). Of the 362 KIBS firms, 97 did not claim to have introduced either a product/service innovation or a process/organisational innovation in the last three years (the reference group); 55 only claimed to have introduced process or organisational innovations; 66 only product or service innovations; while 144 claimed to have introduced both product/service innovations and process/organisational innovations. We included the same set of explanatory variables in the same two step estimation procedure as before.

This found that, when introduced, one of the two 'knowledge bases' variables is highly significant. As anticipated, 'analytical firms' were more likely to innovate (else equal) in only products/services, in only process/organisation, and in both of these. Meanwhile firms identified as having a primarily symbolic knowledge base did not differ significantly from the 'synthetic firms' (all else equal). Other significant variables were size and sector: as expected - larger firms were more likely to innovate, and architecture sector firms were less likely to innovate (c.f., Muller et al., 2008). The only location effect was again surprising. Firms located in towns and rural areas were more likely to claim to have introduced both types of innovation. 
Table 7: Multinomial logistic regressions for introducing different types of innovations

\begin{tabular}{|c|c|c|c|c|c|c|}
\hline & \multicolumn{3}{|c|}{ Model 1: Excludes knowledge bases } & \multicolumn{3}{|c|}{ Model 2 Includes knowledge bases } \\
\hline & $\begin{array}{l}\text { Process/ } \\
\text { Org Only } \\
\text { B (S.E) }\end{array}$ & $\begin{array}{l}\text { Product } \\
\text { /Service Only } \\
\text { B (S.E) }\end{array}$ & $\begin{array}{l}\text { Both } \\
\text { B (S.E) }\end{array}$ & $\begin{array}{l}\text { Process/ } \\
\text { Org Only } \\
\text { B (S.E) }\end{array}$ & $\begin{array}{l}\text { Product } \\
\text { /Service Only } \\
\text { B (S.E) }\end{array}$ & $\begin{array}{l}\text { Both } \\
\text { B (S.E) }\end{array}$ \\
\hline Constant & $-2.148 * * *$ & -0.799 & $-1.327 *$ & $-2.238 * * *$ & -0.869 & $-1.404 * * *$ \\
\hline Size (Ln_Emp) & $\begin{array}{l}0.560 * * * \\
(0.153)\end{array}$ & $\begin{array}{l}0.423 * * * \\
(0.156)\end{array}$ & $\begin{array}{l}0.677 * * * \\
(0.136)\end{array}$ & $\begin{array}{l}0.488 * * * \\
(0.157)\end{array}$ & $\begin{array}{l}0.338 * * \\
(0.160)\end{array}$ & $\begin{array}{l}0.610 * * * \\
(0.139)\end{array}$ \\
\hline Young firm (D) & -0.479 & -0.213 & 0.252 & -0.635 & -0.405 & 0.102 \\
\hline S_ArchEng (D) & -0.279 & $-1.892 * * *$ & $-1.485 * * *$ & -0.275 & $-1.874 * * *$ & $-1.477 * * *$ \\
\hline S_Design (D) & 0.607 & $-0.617^{(13 \%)}$ & -0.302 & $1.122 *$ & 0.161 & 0.150 \\
\hline L_Inner London (D) & -0.885 & -0.421 & -0.401 & -0.814 & -0.401 & -0.360 \\
\hline L_Outer London (D) & -0.055 & -0.426 & 0.182 & 0.029 & -0.356 & 0.253 \\
\hline L_Other Cities (D) & 0.091 & 0.406 & $0.752^{(12 \%)}$ & 0.000 & 0.290 & 0.678 \\
\hline L_Towns/Rural (D) & 0.581 & 0.779 & $1.007 * *$ & 0.710 & 0.892 & $1.111 * *$ \\
\hline KB_Analytical (D) & Not Incl. & Not Incl. & Not Incl. & $1.521 * * *$ & $1.652 * * *$ & $1.423 * * *$ \\
\hline KB_Symbolic (D) & Not Incl. & Not Incl. & Not Incl. & -0.298 & -0.591 & -0.237 \\
\hline N. & & 362 & & & 362 & \\
\hline Model Chi-square & & $75.1 * * *$ & & & $88.9 * * *$ & \\
\hline$-2 \mathrm{LL}$ & & 758.4 & & & 777.0 & \\
\hline McFadden pseudo $\mathrm{R}^{2}$ & & 0.079 & & & 0.093 & \\
\hline
\end{tabular}

97 firms introduced neither product/service nor process/organisational innovations (reference case); 55 only process/organisational innovations, 66 only product/services innovations, and 144 both types.

(D) indicates a dummy variable.

*** significant at $1 \% ; * *$ significant at $5 \% ; *$ significant at $10 \%$.

\subsection{Relating knowledge bases to Innovation: are there different 'drivers' of innovation?}

The analysis in Section 4.1 indicates that including information on 'knowledge bases' has explanatory power in relation to firms engagement in R\&D and design, and their propensity to innovate. Here, we investigate further whether firms with different 'knowledge bases' (according to our classification) behave differently with regard to their 'drivers of innovation'. Innovation performance is here measured as the introduction, in the last three years, of one or more new or significantly improved product or service. We focus especially on product/service innovation because we consider that the knowledge bases and related investments are more closely connected to product/service innovation than to process/organisational innovation.

To investigate the 'drivers' of (or, in strict empirical terms, 'factors associated with') innovation among these firms, we estimated separate logistic regressions for each set of firms, as categorised by their 'primary knowledge base'. We included the following independent variables in each of the models: (1) Firm size (Ln(employment)); (2) A dummy variable for young firms established in the last ten years; (3) Dummy variables for the original sector classification: S_ArchEng, S_Design and S_ITServ. Note that except when 
there are very few cases - i.e., specialist design among 'analytical firms' and software and IT among 'symbolic firms', two of these were initially included in each model, with the most frequently represented being used as the reference sector; (4) A set of categorical dummies for the share of graduates in the firm's workforce, categorised as follows: $0-5 \%$ of the workforce, $6-20 \%, 21-50 \%$; the reference case was over 50\%; (5) A set of dummy variables for location; (6) An estimate for the intensity of the firm's investment in R\&D: i.e., $\mathrm{Ln}(\mathrm{R} \& \mathrm{D} /$ Employment). This was set to zero if the firm did not invest in $R \& D$; (7) An estimate for the intensity of the firm's investment in design, i.e., $\operatorname{Ln}(\mathrm{Design} / \mathrm{Employment})$. This was set to zero if the firm did not invest in design; (8) An estimate for the intensity of the firm's investment in branding and reputation i.e., $\operatorname{Ln}($ Brand/Employment), set to zero if the firm did not invest in this; (9) An estimate for the intensity of the firm's investment in information technologies, i.e., Ln(IT/Employment), again set to zero if the firm did not invest in IT.

In each case, we began with a fully specified model, and then removed the insignificant variables until the model contained only significant variables, or where the further removal of variables would distort the model (Table 8). We found the following:

- Among KIBS classified as having a primarily analytical knowledge base, the introduction of product/service innovations was positively associated with investments in R\&D and IT, but not with investments in design or in branding/reputation. There is (surprisingly) no effect of firm size, but young firms were significantly less likely to have innovated. Firms in the architecture/engineering consultancy sector were also less likely to have innovated than those in software and IT services (i.e., the reference sector). The share of graduates in the workforce had no significant effect on the propensity to innovate, and nor did location.

- Among KIBS categorised as having a primarily symbolic knowledge base, the introduction of product/service innovations was associated with investments in design and IT, but not with investments in either R\&D or branding/reputation. There is no effect of firm size, or any significant sector or location effect, and nor were young firms significantly more or less likely to have innovated. As with the analytical firms, the share of graduates in the workforce had no significant effect on innovation.

- Among KIBS identified as having a primarily synthetic knowledge base, the introduction of product/service innovations was associated with investments in both R\&D and design, as well as in IT, but not with investments in branding/reputation. Here, there was a 
positive effect of firm size, but young firms were not significantly more or less likely to have innovated. As before, the share of graduates in the workforce had no significant effect on the propensity to innovate, but firms in the architecture/engineering consultancy sector were less likely to have introduced innovations (c.f., Muller et al., 2008) than those in software and IT services (from which specialist design firms did not differ significantly). Furthermore, and perhaps surprisingly, KIBS located in smaller nonmetropolitan cities, and towns and rural areas, were found to be more likely to claim to have innovated.

Table 8: Binary logistic regressions for introduction of product / service innovation among the three sub-samples of KIBS firms

\begin{tabular}{|c|c|c|c|}
\hline & $\begin{array}{c}\text { Analytical } \\
\text { KIBS }\end{array}$ & $\begin{array}{c}\text { Symbolic } \\
\text { KIBS }\end{array}$ & $\begin{array}{c}\text { Synthetic } \\
\text { KIBS }\end{array}$ \\
\hline Constant & $1.113 * *$ & $-1.051 * * *$ & $-2.651 * * *$ \\
\hline Young Firm (D) & $-1.231^{*}$ & Deleted & Deleted \\
\hline $\operatorname{Ln}(\mathrm{Emp})$ & Deleted & Deleted & $\begin{array}{c}0.363 * * \\
(0.142)\end{array}$ \\
\hline Sector_ArchEng (D) & $-1.861 * *$ & Deleted & $-1.040 * *$ \\
\hline Ln(R\&D/Emp) & $\begin{array}{c}0.258 * * \\
(0.109)\end{array}$ & Deleted & $\begin{array}{c}0.218 * * * \\
(0.071)\end{array}$ \\
\hline Ln(Design/Emp) & Deleted & $\begin{array}{c}0.144 * * \\
(0.065)\end{array}$ & $\begin{array}{c}0.210 * * * \\
(0.058)\end{array}$ \\
\hline Ln(IT/Emp) & $\begin{array}{c}0.234 * * \\
(0.119)\end{array}$ & $\begin{array}{c}0.155^{* * *} \\
(0.060)\end{array}$ & $\begin{array}{c}0.173 * * * \\
(0.059)\end{array}$ \\
\hline Loc. City (D) & Deleted & Deleted & $1.417 * *$ \\
\hline Loc. Towns/Rural (D) & Deleted & Deleted & $1.265^{* *}$ \\
\hline $\mathrm{N}$ observations & 73 & 119 & 167 \\
\hline$\%$ Innovating & $75 \%$ & $48 \%$ & $58 \%$ \\
\hline Correct No \% & $56 \%$ & $69 \%$ & $78 \%$ \\
\hline Correct Yes \% & $93 \%$ & $63 \%$ & $84 \%$ \\
\hline Model $\chi^{2}$ & $18.3^{* * *}$ & $14.9 * * *$ & $79.8 * * *$ \\
\hline$-2 \log -\mathrm{LL}$ & 63.2 & 149.8 & 146.6 \\
\hline Nagelkerke $\mathrm{R}^{2}$ & 0.330 & 0.157 & 0.512 \\
\hline
\end{tabular}

(D) indicates a dummy variable. $* * *$ significance at $1 \%,{ }^{* *}$ at $5 \%, *$ at $10 \%$

Insignificant variables have been deleted. Other deleted (insignificant) variables not shown above are: dummy variable for the specialist design sector; investment in brand/ reputation ( $\operatorname{Ln}(B r a n d)$ ); categorical variables for the share of graduates in the workforce. 
These estimations show interesting differences. In particular, and in line with prior expectations, investments in $\mathrm{R} \& \mathrm{D}$ are associated with product/service innovation among KIBS with a primarily analytical knowledge base, while investments in design are not important, but the opposite was the case among the firms with a primarily symbolic knowledge base. Meanwhile, both R\&D and design are both associated with product/service innovation among the KIBS with a primarily synthetic knowledge base. Notable also is that investments in IT were positively associated with product/service innovation in all three groups of KIBS firms, while investments in branding and reputation were never significant.

The varying strength of these models is also notable. The final model for the 'analytical firms' had a Nagelkerke pseudo R-square of 0.330 . Because most of these firms claimed to have introduced a product/service innovation, this model was more successful at identifying innovators than non-innovators, but overall it was highly effective. The model for the 'synthetic firms' was also strong; with a Nagelkerke pseudo R-square of 0.512 , it correctly classified $78 \%$ of the non-innovators and $84 \%$ of the innovators. The model for the 'symbolic firms' was notably weaker. Having a Nagelkerke pseudo R-square of 0.157 ; it correctly identified $69 \%$ of the non-innovators and $63 \%$ just of the innovators. ${ }^{16}$

\section{Discussion}

The conviction behind this study is that KIBS (and indeed other firms) are differentiated in their knowledge bases, and moreover that KIBS firms with different (primary) knowledge bases tend to have different characteristics and to tend to behave differently. To this end, we applied the conceptual model of three 'knowledge bases' developed by Asheim and colleagues to firms in three KIBS sectors. To identify knowledge bases, we drew on information publicly available in firms' websites and were able to first manually classify firms with a high level of inter-rater agreement. It is worth noting that aside from their word content, the websites for different 'types' of firms typically present information in strikingly different ways, which made KIBS with a (primarily) symbolic knowledge base especially distinctive, but those with a primarily analytical knowledge base were also fairly easily identified.

\footnotetext{
${ }^{16}$ Note also that a model (not reported due to space restrictions) for the manufacturing firms was also strong, with a Nagelkerke pseudo R-square of 0.463 ; this correctly classified $80 \%$ of the non-innovators and $72 \%$ of the innovators. Furthermore, as a robustness check we also estimated models in which we replaced the expenditures on R\&D, Design, IT and Branding/Reputation with both dummy variables indicating whether or not the firm had invested in each of these activities. The results were fundamentally the same.
} 
We then identified and extracted specific words associated with two of the three 'knowledge bases', and, with the help of a software programme, confirmed two sets of words associated with 'symbolic' and 'analytical' knowledge. Our success with the former is particularly notable, because hitherto a challenge with this conceptual model has been empirically identifying 'symbolic knowledge' and firms based on this (without relying on SIC or occupational codes). Our failure to identify a set of words associated with 'synthetic knowledge' is also notable. As our work progressed, we increasingly took the view that synthetic knowledge may lie between analytical and symbolic knowledge, which are more extreme types on a spectrum, as opposed to there being three distinct types. So although a firm could conceivably be associated with a single 'knowledge base', most are likely to combine knowledge bases to varying degrees, roughly in a continuum from (pure) analytical knowledge to (pure) symbolic knowledge (Strambach, 2008). Virtually all firms apply some pragmatic, synthetic knowledge (Kogut and Zander, 1996), although this may be in the background rather than in the foreground of their activities.

Having categorised the firms by their primary (or most explicit) knowledge base, we then related this categorisation to the firms' characteristics and strategies, particularly in relation to investing in $R \& D$ and design, and then in relation to their propensity to innovate.

With regard to 'explaining' engaging in $\mathrm{R} \& \mathrm{D}$ and/or design, and the propensity to introduce different types of innovation, it must be conceded that, overall, the models were not particularly strong, but nonetheless the addition of the variables relating to the 'knowledge bases' significantly strengthened the models beyond the explanatory power provided by fundamental characteristics including size, age, location and (SIC) sector. For example, we found, as anticipated, that after controlling for other characteristics, KIBS categorised as having a primarily analytical knowledge base were more likely to invest in both R\&D and design, while those identified as having a primarily symbolic knowledge base were significantly less likely to do this. Meanwhile, primarily analytical knowledge based KIBS were significantly more likely to introduce all types of innovations. This indicates that the classification of KIBS firms by their (primary) 'knowledge bases' has explanatory power, and moreover, that this categorisation complements rather than replaces the established Standard Industrial Classification. ${ }^{17}$

\footnotetext{
${ }^{17}$ Note here that this is after the 'cleaning' of categorisation of firms to SIC codes. We were surprised, indeed somewhat alarmed, by the sizable share of firms which appear to have been classified to the wrong SIC code. This was particularly commonplace among the architecture and engineering consultancy firms, but was also found among firms in the other sectors as well.
} 
Our separate modelling of the 'drivers' of product/service innovation among the three categories of firms found more substantial differences, in both the strength of the models, and the factors associated with innovation within each category. With regard to the strength of the models, it is notable (but perhaps unsurprising) that the models for KIBS identified as having a primarily symbolic knowledge base were significantly weaker than those for the other categories for firms. This probably reflects the fact that much less is known about innovation (and its key drivers) in symbolic activities as compared to technological activities, which analytical and synthetic knowledge bases relate to. With regard to the 'drivers of innovation', our findings are broadly in line with our prior expectations: investing in $R \& D$, for instance, is strongly associated with product/service innovation in firms with a primarily analytical or synthetic knowledge base, but has no effect among those with a symbolic knowledge base (which are in any case much less likely to engage in R\&D). Meanwhile, investing in design is significant for KIBS with a symbolic (or synthetic) knowledge base, but not for those with a primarily analytical knowledge base. As our 'synthetic knowledge base firms' are closest to Pavitt's (1984) specialist suppliers, our finding that design is important to these firms aligns with his insight that design is a key driver of innovation amongst such firms. ${ }^{18}$

Three other findings are worth noting. First, that recent investments in information technologies were associated with product/service innovation among KIBS categorised to all three knowledge bases. This indicates that IT investments are particularly important for innovation among KIBS. It does not mean that IT is used in the same way, however.

Second, and by contrast, none of our models of innovation (or engaging in R\&D and/or design) found a significant effect for the share of graduates in the workforce. In other words, KIBS firms with a low share of graduates were just as likely to innovate as those with a high share. This is interesting, because it is assumed that one of the reasons why KIBS are highly innovative is because they are 'knowledge intensive', and 'knowledge intensity' is typically measured by the share of graduates in the workforce. Our finding that KIBS that rely more heavily in highly educated people (i.e., graduates) are not more likely to introduce innovations than those that rely less on graduates begs the question why not? It may be that the measures of innovation used here overlook how graduates contribute. For example, firms

\footnotetext{
${ }^{18}$ More generally we find that all three sets of firms were more likely to invest in design than R\&D, which indicates this is an important (but relatively neglected) activity. We suspect, that 'design' covers a variety of activities (ranging from the identification of customer needs; ideation and creativity, selecting ideas for products/services; the development of technical specifications; implementing products/services; and form giving) rather than a specific activity. Our findings indicate the need to explore deeper what design is, and how it contributes to both competitiveness and innovation, especially in contexts of high symbolic content (c.f., Ravasi and Stigliani, 2012; Eisenman, 2013; D'Ippolito, 2014)
} 
with a high share of graduates might be providing more flexible, customised services, while those with fewer graduates might provide more standardised services (Tether et al., 2001); ironically, the move towards standardisation can increase rather than decrease innovation as measured by the Oslo Manual / CIS (Hipp et al., 2000).

Third, and perhaps surprisingly, we find little evidence that the behaviours of the firms differed greatly with geographical location. There is some evidence that KIBS with a primarily symbolic knowledge base are more likely to locate in inner London, while synthetic firms are more dispersed, but all firm types are found in all types of locations. Perhaps surprisingly, we find that KIBS located in smaller, non-metropolitan cities are more likely to engage in design (but not R\&D), while firms located in towns and rural areas are more likely to claim to have introduced innovations. Furthermore, among KIBS classified as having a primarily synthetic knowledge base, those located outside of metropolitan areas (i.e., in smaller cities and towns and rural areas) were more likely to introduce product/service innovations. All of these indicate that KIBS firms located in non-metropolitan areas are more active at innovation activities, which we had not anticipated, and which contradicts research which tends to suggest larger cities are more advantageous for innovation (e.g., Cooke et al., 2002). The relationship between knowledge bases, locational choices and (innovation) performance is a matter for further research.

\section{Conclusions}

Knowledge intensive business services are increasingly recognised as being among the most dynamic sectors of advanced economies, not only achieving high rates of innovation but also helping their clients to innovate, and research on KIBS has hitherto emphasised how they are distinctive from other firms, and especially product-based manufacturers and operational services. By contrast, relatively little research has sought to examine variety within KIBS. In this paper we have sought to advance this understanding of variety among KIBS by applying a conceptually informed categorisation of knowledge bases, and used this to identifying empirically the primary knowledge bases of KIBS firms active in three sectors. Moreover, we have developed a method which successfully draws on information available on company websites to distinguish between 'analytical' and 'symbolic' knowledge orientations, and have shown that this categorisation contributes to explaining differences in behaviour among KIBS, including their investments in $\mathrm{R} \& \mathrm{D}$ and design, and their propensities to innovate. Beyond this, we have found substantial and significant differences between the investments that KIBS firms with apparently different primary knowledge bases tend to make and which 
are associated with the introduction of innovations. The operationalisation of the SAS knowledge bases model as executed in this paper therefore has value in explaining some of the variety among KIBS. As such, we consider that this paper has helped to 'open the black box' to a fuller understanding of this variety.

There is, however, more to be done, and we conclude with some suggestions for further research. In particular, we suggest that additional work is needed to:

1. Identify synthetic knowledge empirically. While we were reasonably satisfied that we could do this manually, we were not able to find a set of words on websites clearly associated with a synthetic knowledge base, and were therefore unable to identify this through a computer based analysis.

2. Add other 'knowledge bases' to the conceptualisation. In this paper we applied Asheim's and colleagues three 'knowledge bases' model to three KIBS sectors to which we considered it particularly well suited. But we also deliberately excluded other sectors, notably accountancy and legal services, because none of the SAS knowledge bases relates well to the knowledge of laws and regulations, which are at the core of those services. This implies there is a need to conceptually and empirically identify other 'knowledge bases', such as one based on knowledge of laws and regulations.

3. A related need is to develop measurement scales. In this paper we identified KIBS firms by their primary, or most explicit 'knowledge base'. A more sophisticated approach would recognise that multiple knowledge bases can co-exist within a firm, and that the strength of each can vary. One conjecture is that the high performing firms are ambidextrous and able to simultaneously engage in multiple knowledge bases. However, the empirical identification of multiple knowledge bases requires the development of scales to measure each, and this presents a significant methodological challenge.

4. The measurement of innovation could be reconsidered. In this paper we applied the standard Oslo Manual / CIS measures, but we question whether these are unbiased in being equally appropriate to all firms, including those that are project-based, those that engage in a high degree of customisation and/or those that work primarily with symbols rather than technologies, where the distinctiveness of innovations may be difficult to identify.

5. Another challenge is to incorporate dynamics, including the dynamic links between knowledge base(s), innovation and performance. Because we only have cross sectional evidence, we have assumed in this paper that the knowledge base(s) applied by the 
KIBS firms in our analysis are fixed, and that firms do not migrate from one primary knowledge base to another. This is possibly an erroneous assumption, and it would be interesting to examine whether or not firms can and do change their main knowledge base, and how the dynamics of their knowledge bases relates to the dynamics of firms' financial and innovation performance.

We consider that these points provide a rich and interesting research agenda with respect to KIBS, their knowledge bases, characteristics and behaviours. But there is also a wider agenda concerning 'knowledge bases', because the concepts and methods outlined in this paper can be applied more widely, to other, non-KIBS firms, and we would encourage the development of such work. 


\section{Acknowledgements}

Katia Pina gratefully acknowledges funding from the R\&D Management Association (RADMA). Bruce S. Tether gratefully acknowledges funding from the UK-IRC, a research centre jointly funded by the Department for Business Innovation and Skills, NESTA, Technology Strategy Board, and the Economic and Social Research Council (ESRC Ref. RES-598-28-0001) and further support from the European Commission's Seventh Framework Programme, under grant agreement CRE8TV.EU - 320203. These sponsors enabled this research but have had no direct influence on the conduct of the research, or on the preparation of the article, including on the content of the article and the interpretation of the findings; nor have we been pressurised to seek publication of this article by the sponsors or anyone else.

The authors also gratefully acknowledge the assistance provided by Nick Crossley and Martin Everett that enables us to UCINET programme, and for the comments received on previous version of the paper, specially from Keld Laursen, and the three anonymous reviewers. 


\section{References}

ALVESSON, M. 1990. Organization: From substance to image? Organization Studies, 11, 373-94.

ASHEIM, B. T. \& COENEN, L. 2005. Knowledge bases and regional innovation systems: Comparing Nordic clusters. Research Policy, 34, 1173-1190.

ASHEIM, B., COENEN, L., MOODYSSON, J. \& VANG, J. 2007. Constructing knowledge-based regional advantage: Implications for regional innovation policy, International Journal of Entrepreneurship and Innovation Management, 7(2-5), 140-155.

BALMER, J. \& GREYSER, S. 2002. Managing the multiple identities of the corporation. California Management Review, 44(3), 72-86.

BESSANT, J. \& RUSH, H. 1995. Building bridges for innovation: the role of consultants in technology transfer. Research Policy, 24, 97-114.

BIS, 2012. Industry Strategy: UK Sector Analysis, BIS Economics Paper No. 18, Department of Business Innovation and Skills, HM Government, London.

BIS, 2013. Growth is Our Business: A Strategy for Professional and Businesss Services, Department of Business Innovation and Skills, HM Government, London.

BORGATTI, S.P., EVERETT, M.G. and FREEMAN, L.C. 2002. Ucinet 6 for Windows: Software for Social Network Analysis. Harvard, MA: Analytic Technologies.

BRONN, A. \& MARTINSEN, H. 2006. A Reflective Approach to Uncovering Actual Identity", Peggy Simcic Brønn, Andreas Engell and Håvard Martinsen, publisert i European Journal of Marketing, .40(7/8), 886-901.

BULLOCK, M. 1983. Academic Enterprise, Industrial Innovation and the Development of High Technology Financing in the United States. London: Brand Brothers \& Co.

CAPPETTTA, R., CILLO, P. \& PONTI, A. 2006, Convergent designs in fine fashion: an evolutionary model for sytlistic innovation, Research Policy, 35(9), 1273-1290.

CASTELLACCI, F. 2008. Technological paradigms, regimes and trajectories: Manufacturing and service industries in a new taxonomy of sectoral patterns of innovation. Research Policy, 37, 978-994.

COENEN, L. \& MOODYSSON, J. 2009. Putting constructed regional advantage into Swedish practice, European Planning Studies, 17(4), 587-604.

COOKE, P., DAVIES, C., WILSON, R., 2002, Innovation advantages of cities: From knowledge to equity in five basic steps, European Planning Studies 10(2), 233-250.

CONSOLI, D. \& ELCHE-HORTELANO, D. 2010. Variety in the knowledge base of Knowledge Intensive Business Services. Research Policy, 39, 1303-1310.

CONSOLI, D. \& ELCHE, D. 2013. The evolving knowledge base of professional service sectors. Journal of Evolutionary Economics, 23, 477-501.

CRICCUOLO, P., SALTER, A. \& SHEENAN, T., 2007. Making Knowledge Visible: Using expert pages to map capabilities in professional service firms, Research Policy, 36, 1603-1619.

D'IPPOLITO, B. 2014. The importance of design for firms' competitiveness: a review of the literature, Technovation, 34(11), 716-730. 
DANIELS, P. W., MOULAERT, F. (eds), 1991. The Changing Geography of Advanced Producer Services. London: Belhaven Press.

DAVIES, A. , FREDERIKSEN, L. ("Project-based innovation:The world after Woodward" In Technology and Organization: Essays in Honour of Joan Woodward. Book Series: Research in the Sociology of Organizations-A Research Annual (29), 177-215

DOLOREAUX, D., FREEL, M. AND SHEARMUR, R., 2010. Knowledge Intensive Business Services: Geography and Innovation, Ashgate, Farnham.

EISENMAN, M. 2013. Understanding Aesthetic Design in the Context of Technological. Evolution. Academy of Management Review 38(3), 332-351.

ESPON 2007. Espon project 1.4.3: Study on Urban Functions, Final Report (available at: http://www.espon.eu/export/sites/default/Documents/Projects/ESPON2006Projects/StudiesScient ificSupportProjects/UrbanFunctions/fr-1.4.3_April2007-final.pdf),

EUROPEAN COMMISSION, 2009. "Challenges for EU support to innovation in services - Fostering new markets and jobs through innovation", PRO INNO Europe Pa per no. 12, Commission Staff Working Document, SEC (2009) 1195 of 09.09.2009.

EVANGELISTA, R. 2000. Sectoral patterns of technological change, Economics of Innovation and New Technology, 9(3), 183-222.

EVERETT, M. G. \& BORGATTI, S. P. 2013. The dual-projection approach for two-mode networks. Social Networks, 204-210.

GERTLER, M. S. \& LEVITTE, Y. M. 2005. Local Nodes in Global Networks: The Geography of Knowledge Flows in Biotechnology Innovation. Industry \& Innovation, 12, 487-507.

GIBBONS, M., LIMOGES, C., NOWOTNY, H., SCHWARTZMAN, S., SCOTT, P. \& TROW, M. 1994. The New Production of Knowledge: The Dynamics of Science and Research in Contemporary Societies, London Sage.

GILLSEPIE, A. E., \& GREEN, A. E. 1987. The changing geography of producer services employment in Britain. Regional Studies, 21, 397-411.

GIOIA, D. A. \& THOMAS, J. B. 1996. Identity, Image, and Issue Interpretation: Sensemaking During Strategic Change in Academia. Administrative Science Quarterly, 41, 370-403.

HIPP, C. 2000. Information flows and knowledge creation in knowledge-intensive business services: Scheme for a conceptualization. In J. S. Metcalfe \& I. Miles (Eds.), Innovation systems in the service economy - Measurement and case study analysis. Boston: Kluwer Academic.

HIPP, C., TETHER, B. S. \& MILES, I. 2000.The incidence and effects of innovation in services: evidence from Germany. International Journal of Innovation Management, 04, 417-453.

HOLLENSTEIN, H. 2003. Innovation modes in the Swiss service sector: a cluster analysis based on firm-level data, Research Policy, 32(5), 845-863

HOWELLS, J. 2006. Intermediation and the role of intermediaries in innovation. Research Policy, 35, $715-728$

JAHNKE, M. 2013 Meaning in the Making: Introducing a hermeneutic perspective on the contribution of design practice to innovation, Doctoral Dissertation, HDK - School of Design and Crafts, University of Gothenburg.

JENSEN, M. B., JOHNSON, B., LORENZ, E. \& LUNDVALL, B. Å. 2007. Forms of knowledge and modes of innovation. Research Policy, 36, 680-693. 
KAKABADSE, N. K., KAKABADSE, A. \& KOUZMIN, A. 2003. Reviewing the knowledge management literature: towards a taxonomy. Journal of Knowledge Management, 7, 75-91.

KING, N. 2004. Using templates in the thematic analysis of text, in C.Cassell and G.Symon (Eds.) Essential Guide to Qualitative Methods in Organizational Research. London: Sage.

KOGUT, B. \& ZANDER, U. 1996. What Firms Do? Coordination, Identity, and Learning. Organization Science, 7, 502-518.

LIU, J., CHAMINADE, C. and BJORN, A. 2013. The geography and structure of global innovation networks: a knowledge base perspective, European Planning Studies, 21(9), 1456-1473

LOVE, J., ROPER, S. \& BRYSON, J.R. 2011. Openness, Knowledge, Innovation and Growth in UK Business Services, Research Policy, 4010, 1438-1452.

LUNDVALL, B.-Ä. \& JOHNSON, B. 1994. The Learning Economy. Journal of Industry Studies, 1, $23-42$.

MALERBA, F. 2002. Sectoral systems of innovation and production. Research Policy, 31, 247-264.

MALHOTRA, N. \& MORRIS, T. 2009. Heterogeneity in Professional Service Firms. Journal of Management Studies, 46, 895-922.

MANNICHE, J. 2012. Combinatorial Knowledge Dynamics: On the Usefulness of the Differentiated Knowledge Bases Model, European Planning Studies, 20(11), 1823-1841.

MARTIN, R. \& MOODYSSON, J. 2011. Comparing knowledge bases: on the geography and organization of knowledge sourcing in the regional innovation system of Scania, Sweden. European Urban \& Regional Studies, 20, 170-187.

MARTIN, R. 2012. Measuring knowledge bases in Swedish regions, European Planning Studies, 20(9), 1569-1582.

Miles, I., KASTRINOS, N., FLANAGAN, K., BILDERBEEK, R., HERTOG, P. D., HUNTINK, W. \& BOUMAN, M. 1995. Knowledge-Intensive Business Services. Users, Carriers and Sources of Innovation. EIMS.

MOODYSSON, J., COENEN, L. \& ASHEIM, B. 2008. Explaining spatial patterns of innovation: Analytical and synthetic modes of knowledge creation in the Medicon Valley life-science cluster, Envirionment and Planning A, 40(5), 1040-1056.

MULLER, E., DOLOREUX, D., 2009, What we should know about knowledge-intensive business services, Technology in Society 31, 64-72.

MULLER, K., RAMMER, C. and TRUBY, J. 2008. The role of creative industries in industrial innovation. ZEW Discussion paper $n^{\circ}$ 08-109, ZEW, Mannheim.

NEUENDORF, K. A. 2002. The content analysis guidebook, Thousand Oaks, CA, Sage.

OECD, 2005. Oslo Manual: Guidelines for Collecting and Interpreting Innovation Data, 3rd Edition, OECD Paris.

OECD, 2012. Policy Report on Service R\&D and Innovation, Working Party of National Experts on Science and Technology Indicators and Working Party on Innovation and Technology Policy, OECD, Paris.

ONS 2002. UK Standard Industrial Classification of Economic Activities 2003, Office for National Statistics, London: HMSO / The Stationary Office. 
ONS 2009. UK Standard Industrial Classification of Economic Activities 2007 (SIC 2007): Structure and Explanatory Notes, Office for National Statistics, London: Palgrave Macmillan.

PAVITT, K. 1984. Sectoral patterns of technical change: Towards a taxonomy and a theory. Research Policy, 13, 343-373.

POLANYI, M. 1967. The tacit dimension, London,, Routledge \& K. Paul.

PREISSL, B. (2000). Service Innovation: What makes it different? Empirical evidence from Germany. In J. S. Metcalfe \& I. Miles (Eds.), Innovation systems in the service economy Measurement and case study analysis. Boston: Kluwer Academic.

RAVASI, D. \& STIGLIANI, I., 2012, Product Design: a Review and Research Agenda for Management Studies, International Journal of Management Reviews, Vol:14, ISSN:1460-8545, 464-488.

ROPER, S., HALES, C., BRYSON, J. R. \& LOVE, J. 2009. Measuring sectoral innovation capability in nine areas of the UK economy. In: PROJECT, R. F. N. I. I. (ed.). London: NESTA.

SCHRICKE, E., ZENKER, A. and STAHLECKER, T., 2012. Knowledge-intensive (business) services in Europe", report published by the European Commission, European Commission, Brussels.

SCOTT, A. J. 1997. The cultural economy of cities. International Journal of Urban and Regional Research, 21, 323-39.

SCOTT, S. G. \& LANE, V. R. 2000. A Stakeholder Approach to Organizational Identity. The Academy of Management Review, 25, 43-62.

SCOTT, A. J. 2007. Capitalism and urbanization in a new key? The cognitive-cultural dimension. Social Forces 85, 1465-82.

SHEARMUR, R., DOLOREUX, D., 2008, Urban hierarchy or local buzz? High-order producer service and (or) knowledge-intensive business service location in Canada, 1991-2001, The Professional Geographer 60(3), 333-355.

STEMLER, S. 2001. An overview of content analysis. Practical assessment, research \& evaluation, 7, 137-146.

STORPER, M., VENABLES, AJ (2004) 'Buzz: face to face contact and the urban economy', Journal of Economic Geography, 4(4), 351-370.

STRAMBACH, S. 2008. Knowledge-Intensive Business Services (KIBS) as drivers of multilevel knowledge dynamics. International Journal of Services Technology and Management, 10, 152174.

STRAMBACH, S. \& DIETERICH, I. 2011. The territorial shaping of knowledge dynamics in BadenWürttemberg Inter-organizational relations in the sectoral knowledge domain of the automotive industry, Vol. 01.11.

TETHER, B. S., HIPP, C. \& MILES, I. 2001. Standardisation and particularisation in services: Evidence from Germany. Research Policy, 30, 1115-1138.

TETHER, B. S. \& TAJAR, A. 2008. Beyond industry-university links: Sourcing knowledge for innovation from consultants, private research organisations and the public science-base. Research Policy, 37, 1079-1095.

TETHER, B. S., LI, Q. C. \& MINA, A. 2012. Knowledge-bases, places, spatial configurations and the performance of knowledge-intensive professional service firms. Journal of Economic Geography, $12,969-1001$. 
UNITED NATIONS, 2011. Promoting Innovation in the Services Sector: Review of Experiences and Policies, United Nations, New York and Geneva.

VERGANTI, R. 2008. Design, Meanings, and Radical Innovation: A Metamodel and a Research Agenda. Journal of Product Innovation Management, 25, 436-456.

VERGANTI, R. \& ÖBERG, Å. 2013. Interpreting and envisioning - A hermeneutic framework to look at radical innovation of meanings. Industrial Marketing Management, 42, 86-95.

VON NORDENFLYCHT, A. 2010. What is a professional service firm? Toward a theory and taxonomy of knowledge intensive firms. Academy of Management Review, 35, 155-174.

WOOD, P. (ed.), 2002. Consultancy and Innovation: The Business Service Revolution in Europe. London: Routledge.

WOOD, P. 2009. Knowledge Intensive Business Services. In: EDITORS-IN-CHIEF: ROB, K. \& NIGEL, T. (eds.) International Encyclopedia of Human Geography. Oxford: Elsevier.

WOODWARD, J. 1965. Industrial Organization: Theory and Practice. Oxford: Oxford University Press. 
